\title{
III Congreso Ibérico de Egiptología III Congresso Ibérico de Egiptologia
}

\author{
Miguel Ángel MOLINERO POLO
}

\section{$\mathrm{L}$} os dos volúmenes del número 5 de Trabajos de Egiptología recogen una selección de las comunicaciones, reelaboradas, del III Congreso Ibérico de Egiptología / III Congresso Ibérico de Egiptologia, que se celebró entre los días 11 y 14 de septiembre de 2006 en San Cristóbal de la Laguna. Las instituciones organizadoras fueron la Universidad de La Laguna, a través de su Centro de Estudios Africanos (CEAULL), y el Instituto de Astrofísica de Canarias (IAC). Como en las dos ocasiones que le precedieron, el Primer Encuentro de Investigadores sobre el Egipto antiguo, celebrado en Madrid en abril de 1998, y el II Congreso Ibérico de Egiptología, que tuvo lugar en Barcelona durante marzo de 2001, el alto número de participantes avaló el interés que despiertan estas reuniones, tanto entre los profesionales como entre el público interesado por esta disciplina. En Tenerife intervinieron más de sesenta investigadores/as hispano y luso parlantes, casi la totalidad de los/las que están activos/as en los países que cubría el evento y que trabajan sobre el Egipto antiguo desde sus distintas áreas de especialización. A ellos/as hay que añadir cerca de un centenar de asistentes como oyentes. La Dirección General de Investigación del Ministerio de Educación y Ciencia ${ }^{1}$, el Cabildo de Tenerife, el Museo de la Ciencia y el Cosmos / Organismo Autónomo de Museos y Centros del Cabildo de Tenerife, la Sección española de la International Association of Egyptologists (IAE) y las asociaciones Española de Egiptología (AEDE) e Isfet / Egiptología e Historia intervinieron como Instituciones Colaboradoras. La coordinación de sus distintos modos de actuación permitió que diversas acciones imprescindibles (difusión, financiación de los actos sociales) fueran más fáciles de gestionar por el Comité Organizador, contribuyendo, así, eficazmente al feliz desarrollo del encuentro.

El Comité organizador del Congreso estaba formado por:

Presidente Miguel Ángel Molinero Polo

Vicepresidente Juan Antonio Belmonte Avilés

Secretaria Dulce Montesdeoca Martín

Vocales $\quad \mathrm{M}^{\mathrm{a}}$ Milagros Álvarez Sosa

Lucía Díaz-Iglesias Llanos

Candelaria Martín del Río Álvarez

Noemí Miranda Cáceres

Carmen del Puerto Varela

1. Mediante una acción complementaria, HUM 2006-27339-E, ligada al proyecto de investigación BHA 2003 / 01686 , concedido por la DGICYT del Ministerio de Ciencia y Tecnología. 
Contaron con la intervención de los siguientes especialistas como Comité Científico, los mismos que han intervenido en estos dos volúmenes de Actas:

Miguel Á. Molinero Polo

Josep Cervelló Autuori

José Manuel Galán Allué

$M^{\mathrm{a}}$ Helena Trindade Lopes

Josep Padró i Parcerisa

Antonio Pérez Largacha

José Ramón Pérez-Accino

$M^{\text {a }}$ Carmen Pérez Díe

Covadonga Sevilla Cueva

Los elementos de la imagen gráfica del Congreso fueron obra de Cristóbal Ruiz Medina, profesor de la UDI de Diseño de la Facultad de Bellas Artes de la Universidad de La Laguna, que supo plasmar maravillosamente las ideas que le expresó el Comité Organizador.

El acto inaugural contó con la presencia del Rector de la Universidad de La Laguna, Excmo. Sr. D. Ángel Gutiérrez, y del Profesor Francisco Sánchez Martínez, Director del Instituto de Astrofísica de Canarias. Esta sesión de apertura se clausuró con la primera de las conferencias invitadas, a cargo de D. Antonio Tejera Gaspar, catedrático de Arqueología de la Universidad de La Laguna: Canarias y el África antigua: egipcios y libios. El propósito era dar la bienvenida a los asistentes recordándoles que estaban en una Comunidad autónoma de ubicación africana y que el origen de sus primeros pobladores era tan norteafricano como el propio Egipto. El conferenciante repasó los lazos, lejanos, ligados a un sustrato común, que en el pasado unieron a las poblaciones preeuropeas canarias con las de Libia y del Valle del Nilo, y, sobre todo, fue separando lo que en la actualidad se considera aceptado respecto de las muchas interpretaciones que consideramos erróneas, creadas por los historiadores en los últimos dos siglos, a propósito de supuestos contactos entre ambos grupos humanos o incluso la filiación directa de algunas prácticas aborígenes, como la momificación.

A partir de ese momento se desarrollaron las cuatro jornadas del Congreso, en las que se expusieron 53 comunicaciones a cargo de 62 investigadores/as. Frente a otros Congresos en que el número de exposiciones hace obligado el reparto en salas que funcionan paralelamente, en éste todavía pudimos mantener una sesión única -hubo una sola excepción-, con la ventaja de poder escuchar el conjunto de participaciones y obtener una idea completa del panorama de la Egiptología académica hispano y luso parlante.

Las jornadas se repartieron en dos sedes. De lunes a miércoles se celebró en el Aula Magna del Aulario de Guajara; sólo durante la última mañana fue necesario duplicar una sesión paralela en el Salón de Grados de este mismo edificio. El jueves tuvo lugar en el Museo de la Ciencia y el Cosmos. Estuvieron organizadas de manera que cada día tuviera una temática común. El lunes estuvo dedicado a estudios de Historia; el martes se expusieron las actividades de las Misiones arqueológicas en Egipto y el miércoles trabajos relacionados con Religión e iconografía egipcias; ese mismo 
día se agruparon en una sesión paralela matinal las comunicaciones que incluimos bajo el epígrafe Egipto fuera del Valle del Nilo; por último, el argumento en torno al cual se organizó el jueves fue Museología y renovación de métodos y técnicas. Además, se dio cabida a la presentación de los seis pósters que permanecieron expuestos durante todo el evento para su discusión pública. La lista completa de comunicaciones siguiendo el orden en que fueron presentadas se muestra al final de este texto.

Siguiendo con el propósito de ofrecer actividades complementarias de interés para los participantes a partir de las posibilidades de las dos instituciones organizadoras, la jornada del martes se cerró con otra conferencia invitada, la del Dr. Fernando G. Martín, catedrático de Historia del Cine de la Universidad de La Laguna, que se centró en el Egipto antiguo en el cine egipcio, pues el Arte audiovisual en una de las especialidades de la Facultad de Geografía e Historia de Universidad de La Laguna. El Egipto contemporáneo se ha preguntado a través de distintas aproximaciones por su pasado más remoto, desde su uso como inspiración para la arquitectura y las artes a la novela o el cine. Las obras de este último medio no son tan conocidas para nosotros como las de producción norteamericana o europea. Naturalmente, la perspectiva de directores como Shadi Abd el-Salam o Yusef Chahine es muy diferente a la de los occidentales y en sus trabajos y en la particular sensibilidad de estos autores hacia su pasado faraónico se centró la conferencia. Ésta fue seguida de la proyección de la película El emigrante, la reciente y polémica cinta del segundo de estos directores.

El jueves, en el Planetario del Museo de la Ciencia y el Cosmos, Juan A. Belmonte Avilés y Oswaldo González prepararon la bóveda celeste como podían verla los habitantes del Valle del Nilo hace tres mil años y explicaron cómo la interpretaban y se servían de ella. El cielo sobre Tebas: descifrando constelaciones en el Firmamento del Egipto Antiguo, se convirtió en un modo muy didáctico y visual de explicar los avances del proyecto de investigación "Orientatio ad Sidera: prácticas astronómicas de las civilizaciones antiguas".

La primera conclusión fundamental del Congreso, repetida con entusiasmo por los participantes desde el comienzo del evento, ha sido el elevado nivel de todas las comunicaciones, lo que manifiesta que las Egiptologías académicas representadas están alcanzando un nivel equiparable al de los otros países de mayor tradición en la disciplina. Es cierto que aún hay una distancia en programas de estudio universitarios, calidad de bibliotecas y apoyo de las instituciones públicas y privadas, pero los resultados muestran que es posible superar esos problemas, aunque esto haya que hacerlo, seguramente y en la mayoría de los casos, con un esfuerzo mayor y algunas incomodidades adicionales. Se trata, en definitiva, de la consolidación de la disciplina en algunos centros de docencia e investigación españoles, portugueses, argentinos, que están siendo muy activos en los últimos años.

Una de las ventajas de este tipo de congresos es poder ofrecer el resultado de la actividad investigadora que desarrollamos en nuestras propias lenguas. La Egiptología académica no incluye, en sus idiomas de comunicación, ni el español ni el portugués. Frente a algunas voces que se alzaron en España en los años noventa abogando por la inclusión del español entre ellos, la tendencia general está siendo la contraria, a la par de lo que sucede en el resto de los dominios científicos: la reducción de los vehículos de expresión. Se trata de una simple cuestión de eficacia. Lo sucedido en el X International 
Congress of Egyptologists de Rodas, en mayo de 2008, con el cambio al inglés de la mayoría de las comunicaciones que se habían anunciado en alemán y francés es muy sintomático de la dirección que está tomando esta cuestión. Esto hace aún más necesario que los egiptólogos encontremos vías para difundir nuestro trabajo, también, en la lengua de nuestro país. No tiene sentido que la hagamos sólo en esta última, pues la investigación se realiza para su comunicación. Ésta va dirigida, en primer lugar, a otros investigadores y a los responsables de su aplicación práctica -en el caso de la Egiptología, a los del Patrimonio egipcio en toda su amplitud: monumentos, objetos de museo, textos...-, para los que el español no resulta una vía abierta. En segundo lugar, a todo el que se interese por el avance de la disciplina. En España y Portugal hay una auténtica pasión, en la actualidad, por la civilización del Nilo y esto implica un interés continuo por lo que hacemos, un interés que estamos obligados a cubrir pues es la sociedad la que financia nuestra labor, por lo que también hay que encontrar modos de hacerle llegar el resultado. Estos encuentros son también una vía.

El Congreso se preocupó también por ese aspecto divulgativo: abriendo sus puertas como oyentes a las personas interesadas, que no dejaron de venir en alto número, organizando algunas actividades paralelas de impacto social. Los medios de comunicación social, tanto locales como nacionales, fueron un instrumento muy eficaz en la divulgación de las comunicaciones; el Congreso estuvo presente en ellos a diario: se dedicó espacio en algunos periódicos a los resultados de temas concretos; se realizaron entrevistas, sobre todo radiofónicas, a sus participantes sobre sus actividades específicas y el desarrollo de la profesión; se organizaron mesas redondas televisadas sobre temas de interés popular.

Una de las finalidades de un Congreso regional como éste es la posibilidad de discusión de problemas comunes a los profesionales participantes. Como en toda reunión de este tipo, se pudo hablar sobre temas de implantación universitaria de la disciplina, la integración de especialistas en las instituciones académicas, la relación de los equipos arqueológicos con las autoridades egipcias, la creación y organización de grupos de investigación. Mención aparte tiene la puesta en común de iniciativas realizadas por los responsables de las instituciones encargadas de velar por el patrimonio egipcio conservado en España: la directora y conservadoras de la sección de Egipto y Próximo Oriente del Museo Arqueológico Nacional, el conservador del Templo de Debod, ligado al Museo de San Isidro de Madrid, y la directora y el conservador del Museu Egipci de Barcelona que también estuvieron presentes en el encuentro. Uno de los temas más urgentes de los que pudimos hablar fue la adaptación al nuevo reto que supone el Espacio Europeo de Educación Superior. Cuando se implante, supondrá la reducción del número de créditos en el título de grado, con el consiguiente peligro de desaparición de las asignaturas optativas egiptológicas que habían surgido con el plan de estudios vigente en varias universidades; aún más grave, supondrá también la desaparición de las asignaturas de libre elección, refugio de asignaturas de lengua egipcia también en varios centros académicos españoles. Pero, al mismo tiempo, la estructura de los estudios de postgrado nos dará la oportunidad de intentar crear algún Máster de Egiptología que equilibre la docencia universitaria con respecto a la que se imparte en Europa. De que sepamos asumirlo y unamos esfuerzos depende que demos el último paso para acercarnos al modo de impartición de la disciplina en otros países.

Debemos destacar la variada procedencia de los egiptólogos participantes: España, Portugal, Argentina, México, Estados Unidos de América, Gran Bretaña, Alemania, Egipto. Si bien los Congre- 
sos se concibieron inicialmente como lugar de encuentro de profesionales españoles, en la segunda edición se incorporaron investigadores portugueses y uno argentino y en este Tercero la representación hispanoamericana se ha incrementado en un proceso paralelo al desarrollo de la disciplina en estos países. Al mismo tiempo, el aspecto positivo de la diáspora de egiptólogos españoles en centros de investigación extranjeros va en paralelo a un aspecto negativo, continuación de un fenómeno que no es extraño a nuestra Egiptología, pues se había iniciado con Jesús López en los años sesenta del s. XX: la imposibilidad del sistema académico y de investigación español de dar cabida a todos los egiptólogos que culminan con éxito su etapa de formación doctoral. Con la década de los noventa del s. XX, también ha hecho su aparición la primera generación española de "egiptólogos a tiempo parcial", aquellos que han tenido que recurrir a otros medios de vida para poder continuar la investigación en el tiempo que les deja libre su actividad remunerada. Algunos estuvieron presentes en Tenerife haciendo malabarismos con sus vacaciones para poder asistir al Congreso y como Presidente del Comité Organizador se lo agradezco efusivamente. Otros no tuvieron esa posibilidad y su ausencia reclama la atención de nuestro colectivo.

Los contenidos que se han tratado en estos días han sido variados, pero giran en torno a determinados temas que están marcados por el carácter de los propios grupos de investigación de los países participantes. El número de comunicaciones más significativo es el relacionado con las campañas de excavación en Egipto. Hasta once misiones arqueológicas han presentado sus resultados, lo que supone una presencia firme en el Valle del Nilo. Si tuviéramos que buscar un aspecto negativo, éste sería la relativa homogeneidad de los trabajos emprendidos, pues se centran en el Alto Egipto y en yacimientos funerarios: ningún equipo participante ha dado el salto al Delta, a los oasis o continuado la tarea abierta en la zona que vio nacer la arqueología española en Egipto, Nubia; las únicas excepciones son dos proyectos: el de prospección submarina en la costa del Mar Rojo -aunque en los años posteriores al Congreso esta vía novedosa no ha encontrado continuación- y el de Arqueoastronomía -que en el momento de cerrar estas líneas también ha concluido sus objetivos previstos-; es significativo y honroso que varias comunicaciones se han presentado en colaboración con investigadores egipcios, en paralelo a un incremento de nuestra participación en proyectos con los responsables de Patrimonio en este país. La religión y, con ella, la literatura funeraria, son campos que han tenido también una atención singular. A pesar de que la procedencia universitaria de la mayoría de los egiptólogos es la licenciatura de Historia, los análisis de tipo histórico son menos numerosos que los antes mencionados y un porcentaje muy alto se centra en el estudio de documentos epigráficos muy concretos. Por otra parte, algunas de las lagunas, por el momento, en la Egiptología española, parecen ser la Filología y los estudios de Literatura -ninguna comunicación ha tratado problemas lingüísticos y sólo una se ha centrado en el análisis de un texto literario-, así como las cuestiones epistemológicas, que son una presencia firme en congresos de otras disciplinas históricas.

Una cuestión fundamental ha sido la colaboración de los egiptólogos con especialistas en otras disciplinas que ha tenido como resultado una jornada, celebrada en el Museo de la Ciencia y el Cosmos, de comunicaciones interdisciplinarias. Se mostraba, una vez más, la versatilidad tradicional de la Egiptología para incorporar perspectivas procedentes de disciplinas muy dispares. Así, escuchamos a una abogada que analizó el derecho faraónico, astrónomos que explicaron la concepción egipcia del cielo y su plasmación en la orientación de los templos, médicos que estudian enfermedades y 
prácticas curativas, físicos y diseñadores gráficos que aportan sus conocimientos para establecer nuevos modos de documentar las inscripciones egipcias.

Por último, la comunidad egiptológica hace un nuevo llamamiento, una vez más, pidiendo atención sobre el Templo de Debod. El conservador del monumento ha mostrado en La Laguna los planes para una futura campaña de protección y limpieza del edificio. Sin embargo, consideramos que esto es insuficiente. Los factores de degradación van a seguir afectándolo si no se pone en marcha un proyecto más ambicioso de aislamiento del templo respecto a los elementos de degradación atmosféricos. Contrariamente a la opinión emitida en una reunión reciente de arquitectos, que se manifestaban partidarios de dejarlo a la intemperie y resignarse a su paulatina degradación, los egiptólogos insistimos en que no vamos a conformarnos con observar cómo se dirige hacia la ruina. Por eso, instamos al Ayuntamiento de Madrid, propietario y responsable del santuario, a iniciar un proyecto de protección que incluya cubrirlo lo antes posible. La crítica expresada en el Congreso tuvo un amplio eco en la prensa nacional y llegó a un pronunciamiento de la UNESCO en marzo de 2007 sobre la necesidad de cubrir el edificio y, adicionalmente, a que se concluyera el expediente para incoarlo como BIC poco después (publicado en el Boletín Oficial de la Comunidad de Madrid el 23 de mayo de 2007). Sin embargo, pasado ese primer momento, seguimos sin tener noticias de actuaciones concretas. La crisis económica que atraviesan tanto el Ayuntamiento de Madrid como el conjunto del país no augura nada positivo para este tema tan urgente.

Una más de las consecuencias del Congreso ha sido asegurar la continuidad y periodicidad regular de estos encuentros. Habiéndose fijado durante el II Congreso, en Barcelona, que tendrían lugar cada cuatro años, equidistantes con los que organiza la International Association of Egyptologists, se aceptó la propuesta del Instituto Oriental de la Universidad de Lisboa de celebrar el próximo Congreso Ibérico en esta ciudad, en septiembre de 2010. En el momento de concluir estas líneas, las actividades preparatorias ya se han iniciado.

San Cristóbal de La Laguna, verano de 2009 


\section{COMUNICACIONES}

\section{Lunes 11 de septiembre de 2006}

Tema de la jornada: Historia

Primera sesión - Presidente: José Miguel Serrano

Sales, José das Candeias - A noçao de trasmissao hereditária do poder nas titulaturas dos Ptolomeus

Bosch Puche, Francisco - La titulatura faraónica de Alejandro Magno

Sevilla Cueva, Covadonga - Revisión crítica de la figura de Montuemhat

Lull García, José - Algunas cuestiones cronológicas y genealógicas de la whm mswt y la dinastía $X X I$

Segunda sesión - Presidente: Alfonso Martín Flores

Torre Suárez, Juan de la - La Carta de Amarna EA12: Nueva interpretación y sus consecuencias históricas

Castillo Mallén, Mara - Los deberes o las prerrogativas del visir. Descubriendo a la familia de Rej$m i-r a$

Jaramago Canora, Miguel - La estela del rey Seankhiptah: recientes investigaciones

Cordón i Solá-Sagalés, Irene - Cuatro hijas del rey de la II Dinastía. Análisis epigráfico e iconográfico de las estelas de Hepetkhenmet, Satba, Shepsetipet (?) y Sehefner

\section{Martes 12 de septiembre}

Tema de la jornada: Misiones arqueológicas en Egipto

Tercera sesión - Presidente: Jose das Candeias Sales

Seco Álvarez, Myriam - Prospección arqueológica submarina de la zona entre el Wadi Gawasis y Marsa Alam

Jiménez Serrano, Alejandro - Nuevos grafitos descubiertos en Garb Asuán Sur

Cervelló Autori, Josep - Kom el-Jamasin: epigrafía

Gonzálvez Ortega, Luis Manuel / Belmonte, Cristina / Gamarra, Agustín / Taulé, Mariàngela /

Gomaà, Faruk / Huber, Beatrice - Los trabajos de la Universidad de Tübingen en Kom al-Ahmar/

Sharuna. La participación del Museu Egipci de Barcelona en el año 2006

Pérez Die, Carmen - Novedades arqueológicas en Ehnasya el Medina 
Cuarta sesión - Presidente: Luis Manuel Gonzálvez Ortega

Galán Allué, José Manuel - Los patios de entrada a las tumbas del 'Proyecto Djehuty'Dra Abu elNaga (Luxor)

Menéndez Gómez, Gemma - El trabajo epigráfico de la tumba de Hery (TT 12)

Serrano Delgado, José Miguel - Aproximación a la liturgia de la Apertura de la Boca en la tumba de Djehuty (TT 11)

López Grande, María José / Gregorio, Elena de - Cerámicas del Reino Nuevo con decoración pintada y plástica halladas en Dra Abu-el Naga (excavaciones del Proyecto Djehuty)

Quinta sesión - Presidente: Myriam Seco Álvarez

Pereyra, Maria Violeta - Redes sociales e iconografia

Catania, Maria Silvana / Yomaha, Silvana Lorena - Los rituales de ofrenda y la solarización del culto funerario en la tumba de Neferhotep (TT49)

Castellano i Solé, Nuria - La necrópolis saita de Oxirrinco

Mascort Roca, Maite - El Osireion de Oxirrinco

Pons Mellado, Esther - Últimos descubrimientos en la tumba saita no 14: la cámara no 6 del yacimiento arqueológico de Oxirrinco (El-Bahnasa)

\section{Miércoles 13 de septiembre}

Temas de la jornada: Religión e iconografía egipcias

Sexta sesión - Presidente: José Lull García

Gregorio, Elena de - Estudio iconográfico de las imágenes femeninas en la cerámica Predinástica de Nagada II

Martín del Río Álvarez, Candelaria / Almenara Rosales, Eduardo - Las agujas de pelo y los peines en los ajuares de las tumbas egipcias del periodo Predinástico

Díaz Rivas, Elena - Horus, el huérfano

Miranda Cáceres, Noemí - Seshat en las escenas de fundación de templos y del cómputo de los años reales

Séptima sesión - Presidente: José Lull García

[276] Belmonte Avilés, Juan Antonio / Shaltout, Mosalam - Estableciendo la Maat en Egipto Antiguo: la orientación de los templos

Borrego Gallardo, Francisco Luis - La localización original de las estatuas del templo bajo de Jafra en Guiza: una propuesta

Díaz-Iglesias Llanos, Lucía Elena - Heracleópolis Magna. Lecturas desde la especulación teológica Aja Sánchez, José Ramón - Pervivencias Heliopolitanas en Época Romana: Topónimos y Etimologías egipcias relacionadas con la organización del territorio y la arquitectura religiosa 
Novena sesión - Presidente: Violeta Pereyra

Rull Ribó, David - El “vuelo mágico” del Rey en los Textos de las Pirámides

Morales Rondan, Antonio J. - Un ensalmo de puerta falsa para el rey difunto: Apuntes sobre la localización y función del Ensalmo TP 355

Diego Espinel, Andrés - Los himnos criptográficos en la tumba de Djehuty (TT 11). Posibles orígenes, funciones y contextos

Molinero Polo, Miguel Ángel - Los Textos de las pirámides de la tumba de Harwa (TT 37)

Pujol Peré, Ma del Pilar - El dios Jepri en los Textos de los sarcófagos

Álvarez Sosa, $\mathrm{M}^{\mathrm{a}}$ Milagros - Origen y primera elaboración de la viñeta 110 del Libro de la Salida al Día

Tema de la sesión paralela durante la mañana: Egipto fuera del Valle del Nilo

Octava sesión - Presidente: $M^{\mathrm{a}}$ José López Grande

Méndez Rodríguez, Daniel Miguel - La imagen de Busiris y Memnón en las fuentes clásicas

Couto Martin, Julia - Mosaicos romanos con motivos nilóticos en Hispania

Jevenois Arcillona, Pablo de - El Dioniso egipcio. Titanes y gigantes en el valle del Nilo

Albarrán Martinez, María Jesús - Aurelia Tsone: ¿un ejemplo de vida ascética?

Diego Espinel, Andrés - La colección egipcia del Gabinete de Antigüedades de la Real Academia de la Historia (1858-2006)

Puerto Varela, Carmen del - La divulgación de la Egiptología en España: el ejemplo de la revista Historia National Geographic [se presentó por la tarde, al término de la novena sesión]

\section{Jueves 14 de septiembre}

Tema de la jornada: Museología y renovación de métodos y técnicas

Décima sesión -Presidente: Andrés Diego Espinel

Araújo, Luis de - Os objectos egípcios da reserva do Museo Calouste Gulbenkian

Martín Flores, Alfonso - La conservación del templo de Debod. Problemas y propuestas para el futuro

Cases Martín, Juan Ignacio / González Hernández, Oswaldo Bernabé - Técnicas de trazado de rayos aplicadas al análisis de inscripciones en epigrafía egipcia

Ruiz Medina, Cristóbal / Delgado Corona, Noemí - La gráfica digital aplicada a la epigrafía egipcia. Técnicas y procedimientos visuales

Cardona Arenas, Beatriz - El maquillaje ocular en el antiguo Egipto ¿terapéutica o cosmética?

Sánchez, Miguel A. - La momia de Nesi-Amón del Metropolitan Museum of Art de Nueva York. ¿Accidente o trasplante para la eternidad?

Dinarés Solá, Rosa - íb y ḩ̉ty: El corazón en el Antiguo Egipto 
Décimo primera sesión - Presidente: Luis de Araújo

Soria Trastoy, Teresa - Una aproximación jurídico-teórica al concepto de maat: de maat al Derecho Consuetudinario

Parra Ortiz, José Miguel - La violencia doméstica en el antiguo Egipto

Orriols i Llonch, Marc - Iconografia erótica del antiguo Egipto: la cópula a tergo

Pérez-Accino Picatoste, José Ramón - Literatura como Geografía, Texto como Territorio: El periplo moral de Sinuhé

\section{Pósters}

Almenara Rosales, Eduardo y Martín del Río Álvarez, Candelaria - "Egipto en Tenerife": Los rostros del intercambio

Heras Alonso, Francisco de las - Los "Alcaldes" del Alto Egipto en torno al Reino Medio

Jaramago Canora, Miguel y Di Nóbile Carlucci, Laura - El deterioro del templo de Debod: la historia interminable

Pardo Mata, María Pilar - La "Venus de Argin” del Museo Arqueológico Nacional (Madrid): análisis iconográfico

Perez-Accino, José-Ramón - El horizonte de Puimra (TT 39). Notas previas a su estudio y restauración

Puerto Varela, Carmen del - ¿Sabias que los banquetes egipcios sorprendieron a los persas? Descubre algunas referencias sobre Egipto en Ateneo de Náucratis 


\section{Trabajos de Egiptología Papers on Ancient Egypt}

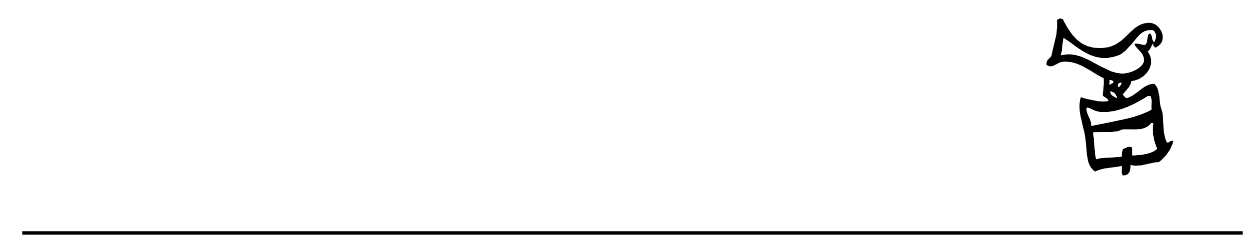

Número 5/2 2009 


\section{Actas \\ III Congreso Ibérico de Egiptología III Congresso Ibérico de Egiptologia}

Editores

Miguel Ángel Molinero Polo Covadonga Sevilla Cueva 


\title{
Editor
}

Miguel Ángel Molinero Polo

Universidad de La Laguna

\section{Consejo Editorial}

\author{
Antonio Pérez Largacha \\ Universidad de Castilla-La Mancha \\ José-R. Pérez-Accino \\ Birkbeck, Universidad de Londres \\ Covadonga Sevilla Cueva \\ Universidad Autónoma de Madrid
}

\section{Comité Científico}

Josep Cervelló i Autuori

Universitat Autònoma de Barcelona

$\mathrm{M}^{\mathrm{a}}$ José lópez Grande

Universidad Autónoma de Madrid

Josep Padró i Parcerisa

Universitat de Barcelona

$\mathrm{M}^{\mathrm{a}}$ Carmen Pérez Die

Museo Arqueológico Nacional, Madrid

Ester Pons Mellado

Museo Arqueológico Nacional, Madrid

José M. Serrano Delgado

Universidad de Sevilla

\section{Colaboradores Editoriales}

Linda Steynor

English editorial assistant

Hervé Mouriacoux

Assistant éditorial pour la langue française 
Trabajos de Egiptología está producida por Isfet. Egiptología e Historia c/ Blanco $1,2^{\circ}$

38400 Puerto de la Cruz

Tenerife-Islas Canarias

España

Maquetación: Proyecto Limón

(C) Autores de los artículos aparecidos

y Consejo Editorial de Trabajos de Egiptología - Papers on ancient Egypt

Depósito Legal: TF-2303-2009

ISSN: $1695-4750$

Imprime: Gráfica Los Majuelos, S.L.L.

imprenta@graficaslosmajuelos.com

Tfno.: 922311455 


\section{Comité Científico \\ III Congreso Ibérico de Egiptología III Congresso Ibérico de Egiptologia}

Miguel Á. Molinero Polo

Universidad de La Laguna

Presidente del Comité Organizador del III Congreso Ibérico de Egiptología

Miembro del Comité Organizador del I Encuentro de Egiptología

Josep Cervelló Autuori

Universitat Autònoma de Barcelona

Presidente del Comité Organizador del II Congreso Ibérico de Egiptologia

José Manuel Galán Allué

Consejo Superior de Investigaciones Cientificas

Director del Proyecto Djehuty, Luxor, Egipto

$\mathrm{M}^{\mathrm{a}}$ Helena Trindade Lopes

Universidad de Lisboa

Directora de la Misión Arqueológica Portuguesa en Menfis

Josep Padró i Parcerisa

Universitat de Barcelona

Director de la Misión Arqueológica de Oxirrinco

Antonio Pérez Largacha

Universidad de Castilla - La Mancha

Miembro del Comité Organizador del I Encuentro de Egiptología

José Ramón Pérez-Accino

Birkbeck College, University of London

Miembro del Comité Organizador del I Encuentro de Egiptología

$\mathrm{M}^{\mathrm{a}}$. Carmen Pérez Díe

Museo Arqueológico Nacional

Directora de la Misión Arqueológica Española en Heracleópolis Magna, Egipto

Covadonga Sevilla Cueva

Universidad Autónoma de Madrid

Miembro del Comité Organizador del I Encuentro de Egiptología 